University of Nebraska - Lincoln

DigitalCommons@University of Nebraska - Lincoln

\title{
Connecting Print and Electronic Titles: An Integrated Approach at the University of Nebraska-Lincoln
}

Judith A. Wolfe

University of Nebraska-Lincoln, jwolfe4@unl.edu

Joan Latta Konecky

University of Nebraska-Lincoln, jkonecky1@unl.edu

Dana W. R. Boden

University of Nebraska - Lincoln, dboden1@unl.edu

Follow this and additional works at: https://digitalcommons.unl.edu/libraryscience

Part of the Library and Information Science Commons

Wolfe, Judith A.; Konecky, Joan Latta; and Boden, Dana W. R., "Connecting Print and Electronic Titles: An Integrated Approach at the University of Nebraska-Lincoln" (2011). Faculty Publications, UNL Libraries. 220.

https://digitalcommons.unl.edu/libraryscience/220

This Article is brought to you for free and open access by the Libraries at University of Nebraska-Lincoln at DigitalCommons@University of Nebraska - Lincoln. It has been accepted for inclusion in Faculty Publications, UNL Libraries by an authorized administrator of DigitalCommons@University of Nebraska - Lincoln. 
Article accepted for publication in Journal of Electronic Resources Librarianship.

Copyright 2011 Taylor \& Francis. Used by permission.

\title{
Connecting Print and Electronic Titles: An Integrated Approach at the University of Nebraska-Lincoln
}

\author{
Judith Wolfe \\ Associate Professor, Subject Librarian, Cataloging and Metadata Librarian, \\ University of Nebraska-Lincoln \\ Joan Latta Konecky \\ Associate Professor, Subject Librarian, \\ University of Nebraska-Lincoln \\ Dana W. R. Boden \\ Associate Professor, Subject Librarian, \\ University of Nebraska-Lincoln
}

\begin{abstract}
Libraries make heavy investments in electronic resources, with many of these resources reflecting title changes, bundled subsets, or content changes of formerly print material. These changes can distance the electronic format from its print origins, creating discovery and access issues. A task force was formed to explore the enhancement of catalog records to increase the connections between print and electronic titles, thus improving patron discovery and access to electronic resources. The investigation considered the relationships between parent and dependent titles, title changes, and publication subsets. The resulting recommendations included interdepartmental cooperation, record-display best practices, and methods for tracking catalog-record enhancements.
\end{abstract}

Keywords: Print and electronic connections, catalog enhancements, patron access, resource access, electronic databases, print migration to electronic, linking electronic resources, title changes, co-location

$\mathrm{F}$ ven in these times of tight budgetary constraints the University of NebraskaLincoln (UNL) Libraries, like other libraries, has made heavy investments in electronic resources. These electronic resources account for an ever-increasing portion of the budget. Many important print titles have migrated to electronic 
format, including major print reference and indexing tools. Frequently these new electronic formats also have been given new titles, have become a subset of bundled products, or their contents have been enhanced. These changes can distance the electronic resources from their print counterpart in the public catalog. Vague or missing connections between print and electronic versions create discovery and access gaps for patrons using the catalog. For example, will the patron

- looking for Psychological Abstracts find the electronic version PsycInfo?

- from the catalog record for the print title Plant Breeding Abstracts, realize that it is part of the merged CAB Abstracts database?

- recognize that the Annual Bibliography of English Language and Literature, though a distinct print title, is a subset within Literature Online, an aggregator database?

Patrons, when finding a record for the print resource, may conclude it is the latest or only available resource and end their search. For serials and continuing titles, cataloging practices, and therefore catalog records, have naturally/automatically provided a form of connection between related, merged, and changed titles. With the migration of major print reference and indexing tools to an electronic format, it is just as important to develop similar cataloging practices that provide connections between titles and related resources.

\section{Approach}

To address these concerns, a task force was formed to recommend catalog enhancements to improve patron discovery of electronic resources. They first recognized numerous connection issues including title changes, new editions, changes in content, and publication subsets.

Next the group identified related issues such as the need for standard cataloging practices, interdepartmental collaboration, and a maintenance process that included an exit plan. Cataloging enhancements were being performed on a case-by-case basis, where the cataloger would devise a solution to fit the particular situation. Incorporating standard cataloging practices would provide consistency. As the practices for cataloging-record enhancement were developed, the need for interdepartmental cooperation and collaboration between subject librarians and catalog librarians was recognized. A maintenance process was important for tracking changes in the records associated with the resources. This would provide the information needed for an exit plan to be used in the event an electronic resource ceases or is cancelled.

Finally, guidelines were developed for the navigational links within the cataloging records, specifying both the wording and placement within the public display. The link could be placed in the bibliographic record either within the 856 MARC field or (in the case of the Innovative Interfaces Inc. [III] system) within a check-in record related to the Electronic Resource Management (ERM) resource record. Depending on its placement in the 856 or the check-in record, the link would appear in a variety of locations in the public display. Consistent placement and language helps the patron recognize and interpret the linking information in the record. 
Wanting cataloging practices to serve patron needs, the task force developed principles to make the catalog a format-blind discovery tool with efficient navigation and connections between strongly related resources. Guided by these principles, the bottom line was: "How will patrons look for this title?" The task force looked to the national guidelines and found that most were oriented toward connecting serial records. These guidelines did not provide a model for related format links for non-serial materials, and therefore were not useful for our enhancement goals.

Among the guidelines examined was a report from the Library of Congress Program for Cooperative Cataloging (PCC) Standing Committee on Automation, Task Group on Linking Entries. This task group was charged with investigating, examining, and establishing criteria for functionality and best practices for linking bibliographic records. They reported "linking entries [in AACR2 are considered as a means to establish] relationships with other resources." (Program for Cooperative Cataloging, 2005) AACR2 recommends the use of notes to acknowledge relationships such as preceding, succeeding, or simultaneously produced material. AACR2, however, does not make specific recommendations regarding the placement or creation of functional links to connect related materials in varying formats.

A review of the MARC format guidelines also provided descriptions and recommendations for the use of notes to identify preceding and succeeding entries. The issue with using notes to connect bibliographic records is that it causes "pseudo-hyperlinking" (Simpson, Lundgren, \& Barr, 2007). This form of linking creates a path from a bibliographic record to a results list, which unfortunately leads to a dead end or circles back to the initial title rather than leading to a related title. This is demonstrated in the bibliographic record for Associations Unlimited (Figure 1).

The document MARC21 Concise Format for Bibliographic Data recommends establishing relationships by connecting the target resource to related titles (Library of Congress, 2009). This linking relationship may be used for three purposes: "related items that assist the user in continuing to search ... related items that have to be obtained physically in order to use the target item ... related items that constitute units of a larger whole" (OCLC, 2008). According to this document, best practices for the display of connecting relationships should include intelligible notes, hot links, and the full history of publication. The connecting information is provided through the use of the MARC fields within the bibliographic record.

The move, from the use of the connecting information in note fields and "pseudo-hyperlinking," (Simpson, Lundgren, \& Barr, 2007) to the use of the 856 field revolutionized record connections. Jay Weitz (2006) supports the use of 856 fields for linking in Cataloging Electronic Resources: OCLC-MARC Coding Guidelines. He discusses separate versus single record creation and electronic reproductions of previously print material. Weitz also provides examples of the appropriate use of the 856 link. He argues that 856 linking may be used as a means to establish electronic location and access information (i.e., text) for an electronic resource. The 856 field may be used when a resource or a subset of a resource is available remotely in order to locate and access the electronic version (Weitz, 2006). Using the 


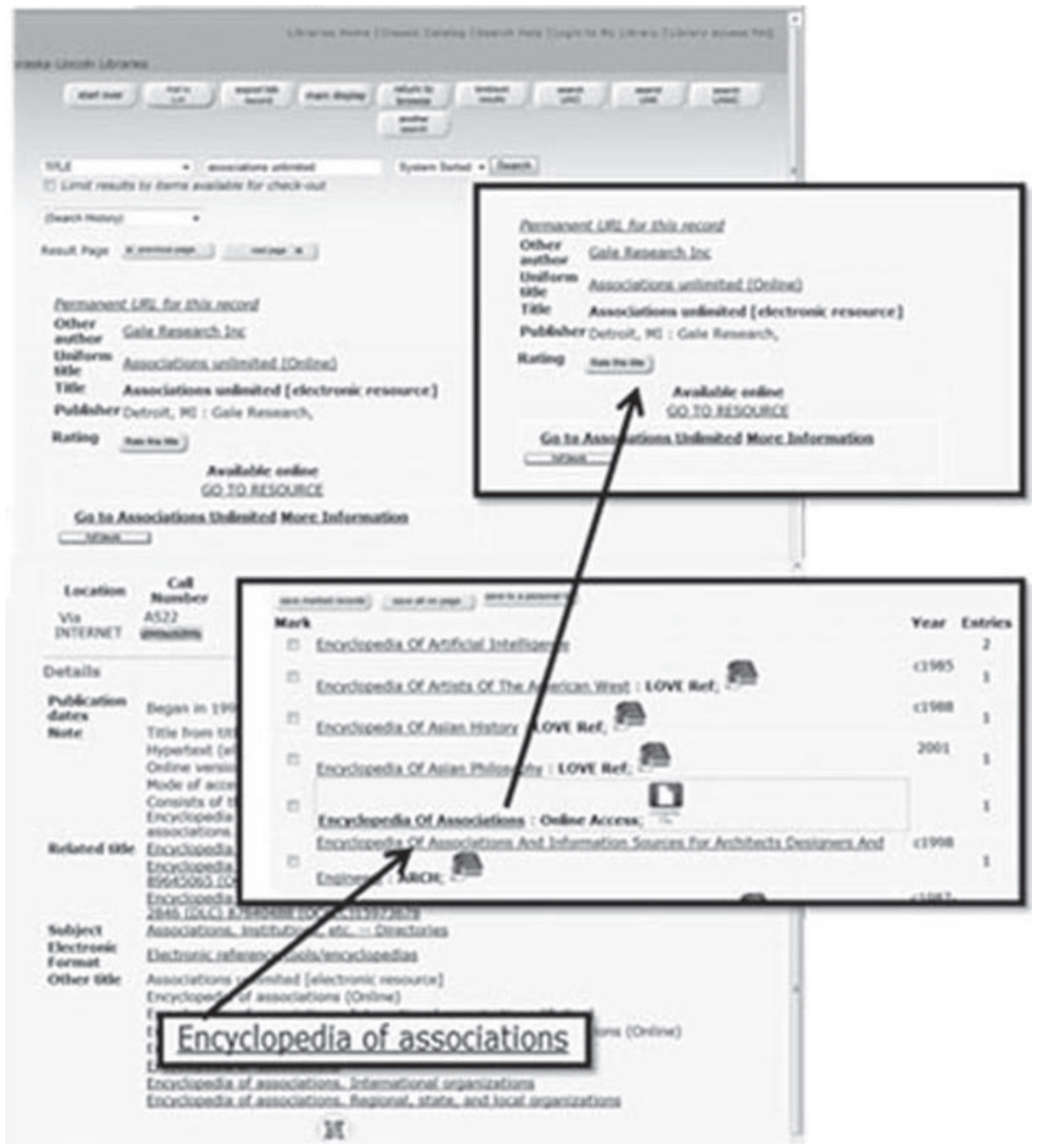

Figure 1. Pseudo-hyperlinking

856 field to make real connections within the catalog record brings the method of connecting print and electronic materials in line with "FRBRizing" (i.e., creating a more effective navigational tool) the OPAC.

The Smathers Libraries at the University of Florida are among the few that have documented a project for creating links between print and electronic records. In explaining the underlying philosophy of their project, they stated, FRBRizing [allows users to] "find, identify, select, and obtain material and to navigate through the catalog database more effectively" (Simpson, Lundgren, \& Barr, 2007). Jennifer Bowen (2005) at the University of Rochester also states the "benefits of implementing the FRBR data model in an online catalog are many including better collocation, more efficient navigation, and better bibliographic control." At both institutions, however, the method is indirect and involves "pseudo-hyperlinking" using the MARC note fields rather than the 856 field. 


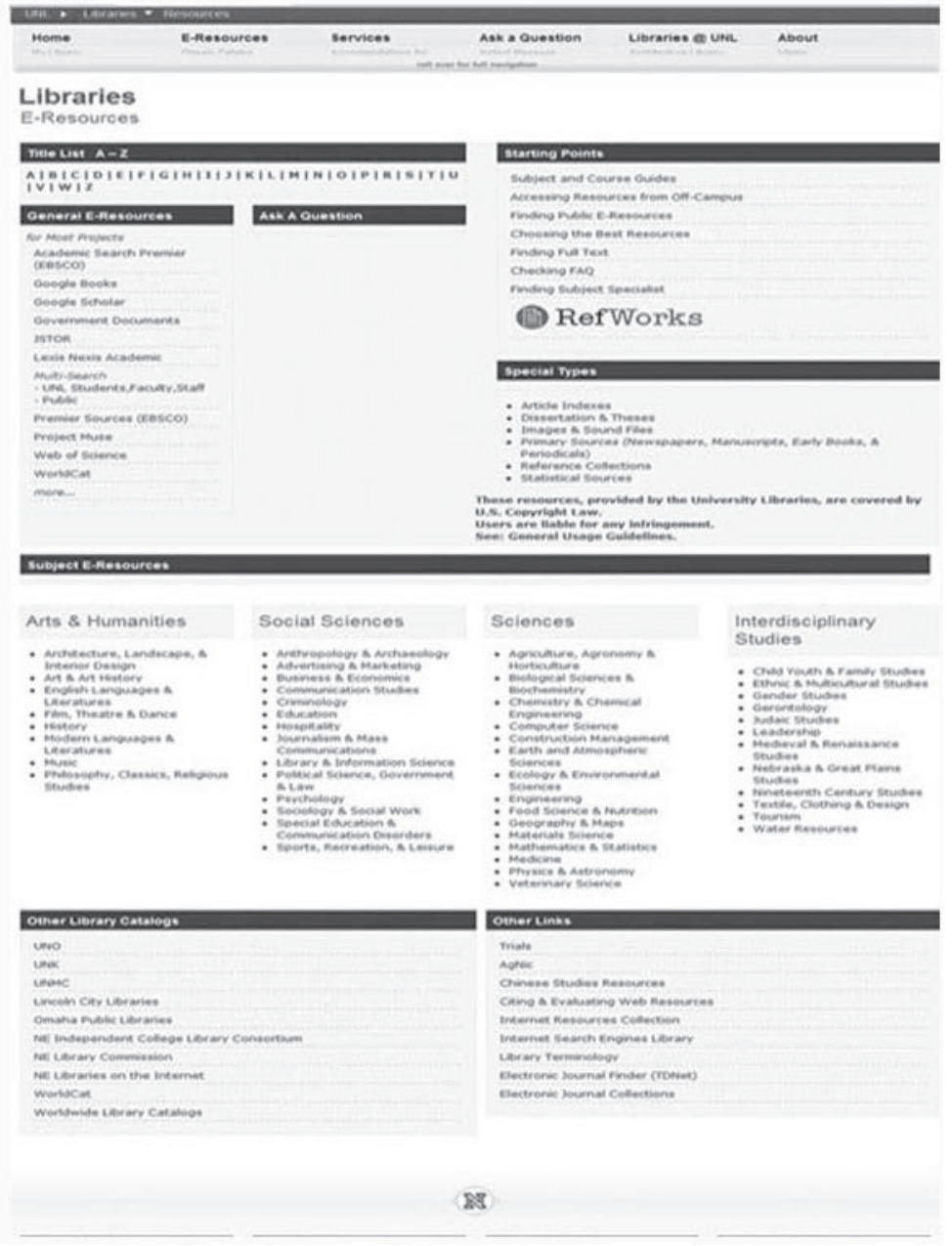

Figure 2. UNL E-Resources Web Page

A recent ARL white paper E-Only Tipping Point for Journals speaks to the evolutionary shift from a primarily print collection to a predominantly electronic collection. As the shift progresses, the importance of discovery through format-blind relationships becomes more and more important. The UNL task force agreed that format-blind access is crucial to overcoming obstacles to discovery and improving user convenience. Format-blind access can be accomplished by including the link(s) to the electronic resource in the bibliographic record for the print material (Johnson \& Luther, 2007).

\section{Process}

The task force chose to focus on resources accessible through the University Libraries E-Resources Web page. 
The e-resources list includes e-journals, databases, and e-book packages. Ejournals and e-book collections were eliminated because the catalog load process automatically creates a link that displays in the library's OPAC. As a result, the review process applied only to the databases.

Of those databases, the task force looked for resources with publication subsets that were not cataloged. They also looked for related print and electronic records that were not already connected in the catalog. Print publications may or may not have the same title as the electronic version, may be a different version but clearly related, or may be the same, a continuation, an update, or an enhanced version. The group decided connections needed to be created between

- title changes that involve print and electronic formats;

- editions that changed to electronic, which may also include a title change;

- added titles, rotating titles, or other changes in content within an umbrella resource;

- and publication subsets (i.e., titles that are included in a larger resource).

\section{Findings and Recommendations}

\section{Cataloging Guidelines}

The review of electronic resources uncovered a few resources that had minimal cataloging records and some that had never been cataloged locally. These included print and electronic versions, which required cataloging, the addition of linking URLs, and/or the creation of added title entries. Therefore the task force recommended a review of cataloging practices related to electronic resources. This led to the development of best practice guidelines incorporating formatblind cataloging. By connecting bibliographic entries for each format, patrons should be able to find the appropriate resources, whether print or electronic.

\section{Making the Connection via 856 URLs}

There are many examples of electronic resources which serve as aggregators and include what were once independent print titles, such as CAB Abstracts online which includes Nutrition Abstracts, Plant Breeding Abstracts, and so on. Another example is Literature Online (LION) which includes the well-known Annual Bibliography of English Language and Literature (ABELL) as one of its subsets. It is useful for these important subsets to have individual cataloging records and connections to the online resource. In some cases, a catalog record existed for the print title. In those cases, the task force recommended adding the 856 field with a direct link to the corresponding electronic resource.

The content and display of links within the OPAC records was also an issue. The clickable link for some records appeared as a URL rather than user-friendly informational text. For these records, the task force recommended identifying and adding informational text phrases to the 856 field.

The informational text in the 856 is critical to patron understanding of the relationship between related resources. This text needed to be clear, informative 


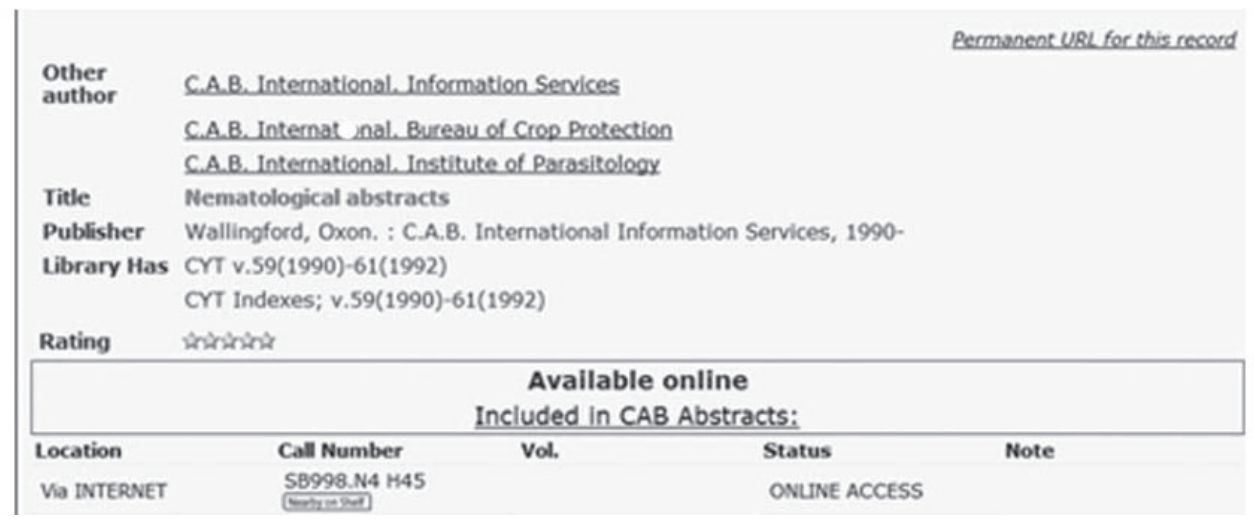

Figure 3. Clickable Display Text

and flexible enough to reflect the transition from print to electronic, including all the variations of title changes, continuations, editions, and publication subsets.

\section{Collaboration}

An important element for the success of enhancement projects is collaboration across departments. Liaison librarians with subject expertise were recognized as having a critical role in identifying the titles to be cataloged and connected. Incorporating the skills and expertise from cataloging, information systems, public services, and vendors provides a broader perspective on patrons' discovery process. Interdepartmental collaboration is also a key factor in developing and revising the policies and procedures for identifying and creating connections between these items.

\section{Documentation}

Membership on the task force was diverse and represented many departments with varying viewpoints. As understanding of the issues evolved lively discussions addressed fundamental differences in philosophical approach, common understanding of terminology, and functional priorities. In addition to documenting the final decisions, it became apparent that maintaining a record of the discussions and the brainstorming of possible solutions was also critically important. The resulting decisions led to the development of procedural guidelines and were codified into a frequently asked questions (FAQ) document (see Appendix A for the FAQ).

Documentation during the bibliographic record enhancement process is also critical. Libraries choosing to use local enhancements need to maintain documentation that allows for tracking and maintenance of the connections. This is essential in the event of changes in the title, the content of the resource, or the link protocol. It may also be used to create an exit strategy in the case of cancellations. Success of the enhancement project depends on a concerted group effort. Enhancement best practices not only need to be understood and adopted by catalogers but also embraced by public services staff and subject librarians. 


\section{Implementation Plan}

In order to transition into the new enhancement process several changes were required. To support communication, a reviewer or review team, composed of subject librarians with a vested interest in its content, was assigned to each resource. In most cases, an e-resource was of interest to multiple subject librarians with overlapping areas of expertise. Once the list of interested subject librarians was compiled, one was designated as the primary contact for each resource. The primary contact would be responsible for keeping the other interested librarians involved in the process. Multidisciplinary e-resources were assigned to the Collection Development Committee, who would designate a librarian to serve as the primary contact when needed.

Several elements in the current cataloging practices were modified. In consideration of the fluid nature of the digital environment and budgets, an exit strategy was created using the parent ERM resource record. The parent record would indicate that dependent or related titles exist. A local note field is then added to the bibliographic record of each dependent or related title to identify the parent ERM resource record. The III create-list function uses the local note to find the appropriate records for reversing the enhancements. Recommendations from the subject librarians were submitted via e-resource transmittal forms (see Appendix B for transmittal form). That form was updated to provide a space for recommending related titles and URL links.

To achieve buy-in for the enhancement procedures the task force held a forum for those with a vested interest, including subject librarians, cataloging librarians, and staff from both technical and public services. At the meeting, taskforce members presented the findings, explained the rationale and shared the best-practice recommendations with this stakeholder group. A key component was to update subject librarians on the general cataloging guidelines for connecting related print and electronic titles. A collaborative attitude was emphasized and encouraged. The forum led to positive discussion and acceptance of the recommendations.

\section{Summary}

The initial charge to the task force was to improve patron access to electronic resources by creating connections between print titles and related electronic resources. Existing standards and guidelines for cataloging were considered, with the primary focus on patron discovery and navigation within a format-blind catalog. To achieve this higher level of patron discovery, the task force decided connections were needed between records for changes in title, edition, or content, and between publication subsets and their parent record.

During the process of crafting the language and format of the connections, the task force also developed best-practice procedures. The procedures incorporated the promotion of multi-departmental collaboration and the development of documentation. The documentation included FAQs, forms, and steps for an exit 
strategy. The implementation strategy involved hosting a forum with demonstrations and discussions.

Recent results of the project have been well received. Public services librarians report that patrons are finding more electronic resources and print equivalents in the catalog. The task force recommendations and resulting procedures have been successful in connecting catalog records, improving resource discovery, and enhancing patron access. The continuing success of the project is dependent upon maintaining strong ties of collaboration and consultation between subject librarians and catalogers for identification of resources to be connected.

\section{References}

Bowen, J. (2005) "FRBR: Coming Soon to Your Library?" Library Resources and Technical Services 49 (3) 175-188.

Johnson, R. K., and Luther, J. (2007) The E-Only Tipping Point for Journals: What's Ahead in the Print-to-Electronic Transition Zone. Washington, DC: Association of Research Libraries,. http://www.arl.org/bm doc/Electronic Transition.pdf (accessed February 13, 2008).

Library of Congress. (2010) "MARC21 Format for Bibliographic Data -- 76X-78X: Linking Entry Fields." http://www.loc.gov/marc/bibliographic/ (accessed March 2010).

OCLC. (2008) “76x-78x Linking Entry Fields -- Introduction.” http://www.oclc.org/bibformats/en/7xx/76x-78x.shtm (accessed March 12, 2009).

Program for Cooperative Cataloging (PCC),(2005) Standing Committee on Automation, Task Group on Linking Entries. Final Report, http://www.loc.gov/catdir/pcc/archive/tglnkentr-rpt05.pdf (accessed February 14, 2009).

Simpson, B., Lundgren, J., \& Barr, T., (2007) “Notes on Operations: Linking Print and Electronic Books, One Approach." Library Resources and Technical Services 51(3) 146-152.

Weitz, J. (2006) "Cataloging Electronic Resources: OCLC-MARC Coding Guidelines." http://www.oclc.org/support/documentation/worldcat/cataloging/electronicresources (accessed February 18, 2008). 


\section{Appendix A}

FAQ document

\section{When are publication subsets (analytics) within electronic resources cataloged?}

"Reference" titles within umbrella electronic resources will be cataloged when cata$\log$ and/or subject specialists consider the titles to be important. It is recommended that catalogers and subject specialists work together to identify these titles and to decide the best way to provide access. An example of a subset is Annual Bibliography of English Language and Literature, which is offered as part of LION.

Records for individual monographs and serials within electronic resources, such as netLibrary or ProjectMUSE, are handled through the acquisition of MARC records or through special projects.

\section{When are multiple records used for related print and electronic resources?}

Electronic resources can be serials, monographs or integrating resources. Most titles on the E-Resources web page are integrating resources. Strictly following AACR2, a separate catalog record is created for each format of a resource. Most libraries do not strictly follow the catalog code in this regard.

Integrating records:

By their nature, electronic resources that are considered integrating resources are of a different format than their print counterparts. However, because of their importance, UNL catalogers have agreed to provide URL links on integrating resource records and their print counterparts.

Serials:

If electronic and print are both serials they will generally be on the same record. CONSER, a cooperative program coordinated by the Library of Congress, has created an option for combining print and electronic serials. UNL follows this option for non-government document serials. Electronic and other formats of a serial will be combined on a print record if the content is identical. If the print and electronic versions are published simultaneously, a single record will be used. If the print has ceased publication, multiple records are used. If the print and the electronic are different material types (i.e., the print is a serial and the electronic is an integrating resource), separate records will be created.

\section{Monographs:}

If the content of one format (e.g. electronic) is considered a reproduction of the other (e.g. print), the records will be combined. Examples are cases where the online is a PDF of the print, such as Gale Virtual Reference Library and Philosophers Index. If the content of the print and the electronic resources are different, separate records will be created.

\section{When are electronic serials connected to records for earlier print serial titles?}

These links are created automatically with "continues" and "continued by" notes. Other connections, such as URLs added to catalog records, may be requested. 
4. When are electronic resources connected to records for earlier print monograph editions?

These links may be requested by the subject specialist.

\section{When are added title entries made to connect related print and electronic records?}

Added title entries may be requested by the subject specialist. Cataloging rules and other factors may come into play when deciding to add a link.

6. When print versions of an electronic resource are not held, what kinds of catalog records are created?

1st choice for both serials and monographs is to use electronic resource records found in OCLC.

2nd choice for serials is to modify a print record. Modified and cloned records will appear basically the same to public patrons. Both can be stripped of information that refers to the print. III uses print and electronic interchangeably.

2nd choice for monographs is to clone print records that reflect e-resource information.

3rd choice is to create mini-bibliographic records when:

a. Access is unstable

b. Resource cannot be viewed separately or described - only its content can be searched

3rd choice is to create original catalog records when:

a. Access is stable

b. Resource can be viewed and described

7. When are links created via a check-in record so that they appear as text within the copy status tab?

Serials: When they are part of the TDnet/ERM coverage file.

Databases: When there is an ERM resource record for the title.

8. When are links created via MARC field 856 so that they appear above the copy status tab?

An 856 is used for government documents and for other resources that are not databases and/or do not have resource records 


\section{Appendix B}

\section{E-RESOURCES TRANSMITTAL FORM}

Complete a separate transmittal form for each title

—NEW PURCHASES _ PUBLIC DOMAIN
ANALYTICAL TITLE
Requester:

Title:

URL:

Analytics umbrella title:

\section{NEW PURCHASES ONLY:}

Bib Record \#:

ISSN/ISBN:

Received as:

Purchase

Gift/Exchange

Licensed

Freely Available/comes with

\section{REQUESTING LIBRARIAN NOTES:}

URL Linking (included all applicable related print or electronic titles)

Title:

Print Electronic

Catalog Only

${ }^{* *}$ Create URL (add to Online Catalog but do not put on IRIS Web pages)

Catalog and include on E-Resource Web page (complete recommendation section)

\section{CATALOGING INSTRUCTIONS:}

Have title cataloged and over-lay the bib record if necessary

Create check-in record with soft link

Catalog cross reference:

Withdraw the ___ format record

Add genre heading for:

Electronic article indexes and databases

Electronic books

Electronic dissertations

Electronic journals

Electronic reference tools/encyclopedias

Electronic maps and atlases

This is an original web title

This is a change of format from to web

Full text database add to TDNet 
Date: Recommended by

Recommendation to the E-Resource Committee (Requesting Librarian)

"Inclusion on the E-Resources page is for items that highlight specific tools because of their importance or their actual or projected frequency of use."

Preferred Title:

Preferred cross reference/s for E-Resource:

Preferred initial screen URL (if possible):

Publication range:

Preferred description (Annotation focusing on content coverage including: coverage dates, types of material, value and use, subject areas, unique features, etc.)

\section{Special Types}

Article Indexes

Dissertation \& Theses

Images \& Sound Files

Primary Sources

Reference Collections

Statistical Sources

\section{Arts \& Humanities}

Architecture, Landscape, \& Interior Design

Art \& Art History

English Languages \& Literatures

Film, Theatre \& Dance

History

Modern Languages \& Literatures

Music

Philosophy, Classics, Religious Studies

\section{Social Sciences}

Anthropology \& Archaeology

Advertising \& Marketing

Business \& Economics

Communication Studies

Criminology

Education

Hospitality

Journalism \& Mass Communications

Library \& Information Science

Political Science, Government \& Law

Psychology

Sociology \& Social Work

Special Education \& Communication Disorders

Sports, Recreation, \& Leisure

\section{Sciences}

Agriculture, Agronomy \& Horticulture

Biological Sciences

Chemistry \& Chemical Engineering

Computer Science

Construction Management
Ecology \& Environmental Sciences

Engineering

Food Science \& Nutrition

Geosciences

Materials Science

Mathematics \& Statistics

Medicine

Physics \& Astronomy

Veterinary Science

\section{Interdisciplinary Studies}

Child Youth \& Family Studies

Ethnic \& Multicultural Studies

Gender Studies

Gerontology

Judaic Studies

Leadership

Medieval \& Renaissance Studies

Nebraska \& Great Plains Studies

Nineteenth Century Studies

Tourism

Water Resources

For use by the E-Resources Committee

Date Reviewed

Add Rejected

Signed 